\title{
Strategies for College Teachers Development in the Era of MOOC
}

\author{
Zhou Junhua ${ }^{1, ~ *, ~ G u o ~ P e n g ~}{ }^{2}$ \\ ${ }^{1}$ Shanghai Branch, Higher Education Press, Beijing, China \\ ${ }^{2}$ School of Mechanical Engineering, Shanghai Jiao Tong University, Shanghai, China
}

Email address:

zhoujunhua99@163.com (Zhou Junhua), guopeng1996@sjtu.edu.cn (Guo Peng)

${ }^{*}$ Corresponding author

\section{To cite this article:}

Zhou Junhua, Guo Peng. Strategies for College Teachers Development in the Era of MOOC. International Journal of Education, Culture and Society. Vol. 5, No. 2, 2020, pp. 26-33. doi: 10.11648/j.ijecs.20200502.12

Received: March 17, 2020; Accepted: April 9, 2020; Published: May 14, 2020

\begin{abstract}
The rapid popularization of "MOOC" (short for Massive Open Online Courses) around the world has brought college teachers abundant high-quality education resources and a lot of opportunities to display their talent, which has broadened their horizon on the teaching reform as well. MOOC has also brought a lot of challenges to college teacher's academic authority and innovation ability. College teachers should not stand still or refuse to make progress. Only by following the trend of big data era, cultivating innovation consciousness, keeping life-long learning, and especially improving information literacy, can the teachers transform resource advantages of MOOC into practicable advantages in their teaching. The development of modern educational technology has a profound impact on teaching. On the one hand, it promotes the reform of teaching methods, optimizes the teaching process, improves the teaching efficiency, and changes the teaching strategies and modes. On the other hand, it also changes the learning environment, improves learning approach, and effectively promotes personalized learning. Teaching is a creative activity, in this process, whether the teacher can reasonably and creatively use modern educational technology has become one of the key factors to improve the quality of teaching. Technological disadvantage and lack of teachers' capability will limit the development of online education. Therefore, it is necessary to further strengthen the research on the application of big data in education, and cultivate special interdisciplinary talents, so as to realize the educational ideal of "teaching students according to their aptitude" as soon as possible. Online education does have some advantages that traditional education cannot match, but we should not blindly overthrow the traditional education system or try to replace it with online education. Online education has actually incomparable advantages over traditional education, but it should be positioned as an important supplement to traditional education, because face-to-face communication between people is still playing an important part of education, and the teacher's guidance to students is still playing a key role in teaching as well. We should not blindly pursue technology, but should adhere to the essence of education. Integration of online and offline teaching will promote the development of education.
\end{abstract}

Keywords: MOOC, Online Course, Online Education, Educational Technology, Teacher Development

\section{Introduction}

MOOC (or MOOCs, short for Massive Open Online Courses), is known as massive online virtual open courses. Through the online platform, teachers and students from all over the world can teach, learn and communicate with each other regardless of time and place. In 2008, two professors from Canada came up with the idea of MOOC. Then came the University of Athabasca in Canada, which pioneered
MOOC by making courses available to students around the world over the Internet, offering topical exchanges and online discussions. 2012 has been called "the first year of MOOC". In this year, the three MOOC platforms such as Udacity, Coursera and edX were launched in the United States, and they have been leading the development of MOOC so far. Universities across the UK have joined the MOOC competition by signing up to the scheme of granting degree for free online course. Since 2012, MOOC has grown rapidly around the world. Universities from the United States, 
Canada, the United Kingdom, China and other countries and regions have joined the research and application of MOOC. Some Chinese domestic major MOOC platforms such as "iCourse" of Higher Education Press, "Xuetang Online" of Tsinghua University and "Good University Online" of Shanghai Jiao Tong University have achieved certain achievements. MOOC is flooding into China's higher education. Some Chinese domestic scholars also conducted relevant studies on the impact of MOOC on China's higher education. For example, Li Fei and Huang Mingdong (2014) [1] proposed the opportunities and challenges brought by MOOC to Chinese universities. Wu Chao [2] and other scholars expounded the possible impact of MOOC on the development of related courses, and proposed the prospect of MOOC. However, few people paid attention to the development strategy for college teachers in this context.

The quality of teachers directly determines the level of a university's education quality. In the new era, it is necessary to promote the professional development by building a team consisting of excellent teachers. [3] In the era of "Internet +", students' way of acquiring knowledge, teachers' way of preaching and solving doubts, and the relationship between teaching and learning have all undergone profound changes, which have put forward new requirements on the ability of college teachers. The development of cloud computing makes teachers and students gradually reduce the use of traditional books and resources. The popularity of mobile learning software makes learning possible anytime and anywhere. Advances in technologies such as instant messaging and social networking have made it easier for teachers and students to participate in social interactions. Facing such changes, the individual teacher must seek teaching-design methods that conform to the law of human education and teaching, and also must implement attractive teaching to promote the evolution of students' learning and thinking modes adaptive to modern society. [4]

In fact, MOOC has brought both opportunities and challenges to Chinese college teachers. How Chinese university teachers should cope with the irresistible development trend and how to seek opportunities in the challenges is a question worth pondering and studying.

\section{The Opportunities Brought by the Wave of MOOC to College Teachers}

\subsection{MOOC Brings Teachers a Large Number of High-Quality Resources and Opportunities to Display Their Talent}

The open learning platform of MOOC provides college teachers with more curriculum resources and teaching services. The high-quality courses developed and produced by famous universities at home and abroad provide abundant resources for university teachers. Teachers can choose the helpful resources for their teaching. Some of the courses are unnecessarily to be developed repeatedly. Even if different students' acceptance is not the same, teachers can also learn from the existing curriculum to develop their own course. The accessibility of quality resources provides more opportunities and convenience for university teachers. These low-cost high-quality resources will lay a foundation for the improvement of college teachers' teaching ability and their personal development.

In the context of MOOC, the integration of educational resources is also a key part to give full play to the positive role of educational technology. In the practice of college education, teachers must be able to combine with the actual requirements of current educational development, actively integrate relevant educational resources, effectively play to the advantages of education, optimize the existing teaching forms, and establish a new college education development system. The full development of educational technology puts forward higher requirements on teachers' ability of integrating resource. However, since many teachers have not got rid of the traditional educational concepts, they may still carry out the traditional and old-fashioned methods, which obviously cannot meet the needs of the development of education in the new era. In other words, the resource integration ability of college teachers still needs to be greatly improved. [5]

Meanwhile, the openness of MOOC also provides an opportunity for excellent college teachers to show their talent. Those pioneer platforms such as "iCourse Network" and "Netease Cloud Course" have cultivated a number of famous teachers, among whom are many young teachers. As it turns out, the MOOC wave has brought more opportunities for some college teachers to display their talent. The infinite expansion of teaching space is also the infinite expansion of their talent display stage. At present, there are a large number of excellent teachers in colleges and universities in China, and the traditional teaching competition activity is a channel for those excellent teachers to stand out in the fierce competition. However, the influence of teaching competition is relatively time-limited and its influence scope is also limited. In the new round of MOOC development and construction, a large number of famous teachers will come into our sight. Their courses will be used online by learners around the world. Excellent courses and outstanding teachers will be more widely recognized. This is an opportunity for college teachers all over the world, especially for those with the ability to innovate and accept new things quickly. They will benefit more from MOOC.

\subsection{MOOC Broadens College Teachers'Vision of Teaching Reform}

After entering the information age, the higher education sector has been exploring new ways of educational informatization. Since the 1960s, the application of information technology in higher education has experienced three stages which are: computer-aided teaching stage (60s to $80 \mathrm{~s})$, computer-assisted learning stage (80s to 90s), information technology and curriculum integration stage (late 90s until now). [6] College teachers have tried to use computer, network teaching platform, social networking 
platform, blog and other information technology means to assist the teaching reform. A lot of results have been achieved. A considerable number of teaching research papers are involved in the application of information technology in higher education. Among them, the most extensive influence is from the using of multimedia-assisted teaching. It has completely changed the long-standing position of chalk in classroom, and also changed the teaching method and thinking way of teachers, which makes the teaching process more three-dimensional.

The rise of MOOC has undoubtedly provided a broad space for the exploration of auxiliary teaching in the information age. By taking this opportunity, college teachers can try to reform their teaching in many aspects. They can be aware of the advantages of resources and platforms brought by MOOC, and make rational use of them to realize the transformation from teaching-centered methods to learningcentered methods. The use of MOOC platform, the exploration of new teaching mode, the design of MOOC, the research and development of MOOC and other fields of MOOC have opened up new ideas of teaching reform for college teachers. At the same time, college teachers can also carry out new teaching reform from various perspectives to inject new vitality into higher education. These perspectives include the selection and construction of teaching resources, the transformation of teachers' concepts about education, the transformation of teaching and learning roles, the development of teachers' career, the cultivation of students' autonomous learning ability, and the mode of talents' cultivation, the study on students' learning motivation and effectiveness evaluation, etc.

\section{The Challenge Brought by the Wave of MOOC to College Teachers}

\subsection{The Authority of College Teachers in Classroom Is Challenged}

Compared with primary and middle school students, college students have a stronger ability of autonomous network learning. They are active and energetic. The MOOC outside the classroom will give them more knowledge, as a result the requirements for teachers' comprehensive ability must be greatly increased. In traditional teaching mode, teacher, classroom and student are the three major elements of education. College teachers are the dominant leaders of classroom and learning space, and they are also the authoritative representatives of relevant courses. In the era of MOOC the educational right is transferred from teacher (education provider) to student (education consumer), [7] and the student will have the right to choose what to study, which may not be completely controlled by the teacher's arrangement. The center of teaching and learning becomes the students, and teaching becomes the construction process of students' learning knowledge, rather than the process of students' passive acceptance of knowledge.

Online courses need teachers to change the teaching concept of "leading the course and students", to put themselves in others' shoes, and they should become guides and helpers of students' learning. In this way, teachers can be equipped with a better capability of information technology application. They should know how to integrate resources, and guide students to carry out inquiry learning with the help of information technology. In terms of students' learning methods, online courses also put forward higher requirements on students' information literacy. Students can learn by relying on the network environment and information technology, which not only meets students' personalized learning needs, but also enables students to communicate and interact with learners from all over the world through the Internet, so as to better internalize knowledge. [8]

Based on this, the improvement of teachers' professional ability also needs to be evaluated from the perspective of the audience, namely, students. Firstly, in the process of classroom teaching, especially in the process of trying to use new methods and approaches, teachers should actively observe the reactions of students, record their learning process, make summary and analysis afterwards to timely adjust their methods. Secondly, teachers should timely observe students' learning effectiveness in class and their homework after class, and then reflect on their own teaching methods and professional skills, so as to constantly improve them. Finally, teachers also need to communicate with students face-to-face. In view of the teaching contents and methods, teachers should listen to the advice raised by students, and maintain good two-way communication, and then continuously find problems in the process of teaching, so as to make optimization, eventually improve their professional ability, as a result the comprehensive effectiveness of teaching will be improved. [9]

At the same time, students' good impression of the lectures on relevant issues given by other famous professors and scholars on MOOC platform will affect their trust in their own teachers' authority in class. MOOC provides quality educational resources that are readily available and students can access any relevant knowledge module. The courses on MOOC platform are well-designed and easy to win approval from students. As for the same course, if the teacher's own explanation is not consistent with that on MOOC platform, it will likely to be questioned by students. So it will be more difficult for young teachers to establish their own academic authority in class. Therefore, the knowledge reserve and academic literacy of college teachers should be strengthened. The era of big data requires college teachers to greatly increase their knowledge reserve.

\subsection{Teachers' Ability to Innovate Is Challenged}

The traditional idea of "teaching-first" still exists in some Chinese colleges at present, and the impact on college teachers in the information age is undoubtedly huge. From a chalk and three-foot platform to computer-aided teaching, then to the wave of MOOC, college teachers are always affected by information technology in their personal development. At the same time, the improvement of students' 
information technology ability also challenges the innovation ability of teachers. In face of the new teaching mode, how to get rid of the imprisonment of traditional teaching concepts will become the key for teachers to conform to the trend of MOOC.

If college teachers stick to the outdated teaching concept and teaching mode without innovation, divergent thinking or reverse thinking, there would be a risk of being swept away by the tide of history. However, the innovation ability of college teachers will be challenged in several aspects: the selection and utilization of curriculum materials and teaching resources, the design and management of classroom activities, the supervision and implementation of student assessment, and the research on education and teaching. It needs teachers to break the old concept and meet new challenges. College teachers may not find the right direction in the MOOC era if they regard teaching and research as a means of making a living instead of a life-long career, or if they do not focus on further learning, do not keep pace up with the times, or they are too confident in their teaching ability without innovation. In the era of MOOC, college teachers are required to advocate not only experience, but also innovation. Outdated knowledge or teaching mode will be gradually eliminated and replaced by new teaching mode full of ideological vitality.

MOOC is the latest organic integration achievement of information technology and higher education. The teaching mode of MOOC has fundamentally disrupted the traditional teaching methods and brought about a huge impact on college education, and students' learning efficiency has become better than before. Under the background of MOOC, college teachers should not only have a good theoretical basis, but also have good education technology application ability, so as to better adapt to the development of massive open online course. But from the point of view of the current actual situation, many university teachers are not skillful enough in conducting educational resource integration. If these problems can't be settled effectively, it will affect the effectiveness of their teaching. Therefore, in this case, indepth analysis of the effective improvement strategy for college teachers' educational technology ability is of positive practical significance for promoting the development of college education under the background of MOOC.

\section{The Development Strategy for College Teachers Under the Wave of MOOC}

\subsection{To Change the Teaching Concept and Explore a Variety of Teaching Modes}

The development of modern educational technology has a profound impact on teaching. On the one hand, it promotes the reform of teaching methods, optimizes the teaching process, improves the teaching efficiency, and changes the teaching strategies. On the other hand, it also changes the learning environment, improves learning approach, and effectively promotes personalized learning. Teaching is a creative activity, in this process, whether the teacher can reasonably and creatively use modern educational technology has become one of the key factors to improve the quality of education.

Whether they like it or not, the coming wave of MOOC has sounded the clarion call for new teaching reform. College teachers must not blindly rely on the traditional teachercentered teaching mode to measure students' learning or control their performance only by test. The teaching-based concept must be thoroughly transformed into a new one, it is necessary to re-position the role of teachers, to update teaching concept and academic research on the new idea of education. Different modes of online and offline such as flipped teaching and blended teaching should be explored to realize diversified teaching.

The original concept of "classroom" - the traditional teaching space, has been extended to the infinite space of the Internet, and the role of teachers also needs to be changed. Both existing learning and teaching theories need to adapt to this development trend. College teachers should take the initiative to face challenges, seize opportunities, make bold innovations, and find new teaching models suitable for curriculum development and talents cultivation. The teacher is no longer merely the teacher of knowledge, but the provider of learning resources, the supervisor of independent learning, the evaluator of learning effectiveness, and so on and so forth. The idea of "teaching people to fish" rather than "giving them fish" will stand out. Teachers should design classroom teaching activities, strengthen teacher-student interaction link management, and conduct learning effectiveness evaluation on the basis of students' autonomic learning so as to improve their ability of autonomic learning and self-directed learning.

\subsection{To Build up an Education Resource Platform and Enhance the Supply Capacity of Online Education Services}

The social changes brought by the "Internet +" era have driven the rapid growth of demand for online learning. At present, some Internet companies have designed online education products mostly to meet the need of students instead of teachers. In fact, facing the new teaching mode, teachers need more teaching resources and guidance materials to support the whole teaching process. In this regard, a standard of database resources could be formulated and an information platform of educational resources could be established by using cloud computing, which will greatly facilitate teachers to use rich teaching resources in the teaching process, and maintain the vitality of the resource library in an open network environment, so as to promote teaching to advance with the times. [10]

Colleges and universities should construct digital curriculum at an appropriate time, improve the quality of education, and train teachers to teach online. At the same time, teachers are encouraged to integrate the scattered curriculum and learning resources. They can cooperate with fellow teachers from other universities to share high-quality 
online digital courses by constructing an inter-school sharing platform. The limited physical space of the university is transformed into a network cyberspace where students can learn anytime and anywhere. The development of online education requires college teachers not only to be the performers of classroom teaching, but also to be the constructors of curriculum learning model by linking inside and outside classroom with the help of network, so as to make students study independently. College teachers should join hands to build a learning community.

\subsection{To Strengthen Their Own Learning Action as a Life- long Learning Teacher}

MOOC will put forward higher requirements on the depth and breadth of college teachers' knowledge. Interdisciplinary learning blurs the boundaries of different subjects and poses more challenges to teachers' academic authority. Teachers must strengthen their own learning, improve academic literacy, and keep life-long learning. A life-long learning teacher should have three basic qualities: First, strong selfstudy ability and innovative spirit; Second, reasonable knowledge structure and strong educational research ability; The third is good coordination and communication skills and the spirit of willing to cooperate. [11] To have these three qualities, college teachers should cultivate their self-study consciousness and innovative spirit. Teachers should not only construct knowledge framework and perfect knowledge reserve in their own professional field, but also optimize their knowledge structure to become an educational researcher. The introduction of new teaching mode is a new challenge for both teachers and students. Teachers should become researchers in this process and solve the problems and perplexities brought by new things.

In the teaching practice of massive open online courses, students usually learn by themselves online. After learning the corresponding knowledge points, college teachers can verify the actual learning effectiveness by designing certain classroom activities. By doing so it can help students establish a complete knowledge system, and then complete the in-depth learning to achieve the expected goals. However, in order to complete such a teaching process, it is necessary for college teachers to have good ability of carrying out targeted teaching activity designing according to the actual situation. Meanwhile, various educational technologies should be actively used in this process to create a relatively relaxing learning environment for students. [12] However, most teachers still encounter some problems that they can not well testify students' learning effectiveness, so their ability of activity designing needs to be improved. [13]

The advent of MOOC brings a new topic to higher education. The issue is about the role of college teachers. To develop and build MOOC, a team is needed. A well-learning teacher should be good at taking the long and making up the short by cooperating with others, and try to learn together and make progress together as a member of the team. The trend of teachers' development in the MOOC era is to concentrate the advantages and cooperate with each other through building an efficient teaching team. Open learning requires open lesson preparation, open teaching and open cooperation. Therefore, college teachers should have an active sense of cooperation to establish a relationship of trust among themselves, and they can learn from each other, so as to improve the overall quality of their teaching.

\subsection{To Meet the Needs of Big Data Era and Improve Information Literacy}

With the rising of MOOC in the era of big data, college teachers are required to have information literacy as well as teaching literacy.

Teaching quality is the premise and foundation for teachers to use educational technology in higher education. If teachers' teaching quality is not good enough and if they lack the understanding of educational technology, it will be impossible for them to effectively play the positive role of technology in educational practice. Massive open online courses are highly technical, so when teachers apply massive open online courses in practice, they must master basic computer technology, and be able to skillfully operate the platform. However, actually just few teachers are proficient in the application of modern education technology. Even if some teachers know a little about certain educational technology, they still show many shortcomings in the actual application process. Therefore, college teachers still have a long way to go in applying educational technology if they want to adapt to the new trend in the context of MOOC. [14]

Firstly, teachers can conduct needs analysis on students' learning and make multidimensional evaluation of teaching based on big data. The era of big data is characterized by diversity, richness and rapid variability. [15] Under the background of the big data era, the analysis of students' needs will be more real-time, and the evaluation of students' learning can be realized by multidimensional comparison with vertical and horizontal perspectives. This requires university teachers to have basic information literacy with the ability of data collecting, analyzing and using relevant software, so as to be able to transform the advantages of teaching resources brought by the era of big data into the advantages of higher education.

Secondly, teachers should learn to use MOOC platform to develop online courses. The use and development of MOOC platform requires not only the professional quality of teachers, but also the relevant information literacy. In the past few decades, China's higher education has undergone a transformation from chalk to multimedia, and most university teachers have been equipped with the ability to use multimedia for auxiliary teaching. In the next decade, we can foresee a new MOOC revolution. College teachers need to follow the trend of the times, learn to make use of MOOC, study MOOC and develop MOOC. The open learning platform brings more convenience for students and more reference materials for college teachers. In addition to basic learning, college teachers can develop and construct new MOOC to meet the new demand of students. Therefore, college teachers should take the initiative to participate in 
relevant training to improve their own information literacy.

\subsection{To Change the Roles of Teachers and Evaluate Teaching Quality in Multiple Ways}

Modern education technology has become an important means in modern teaching and scientific research, it is the necessary precondition of the education modernization. Information literacy is not only the important basic quality of teachers, but also a sign of teachers' competitiveness. It raises our deep understanding of connotation of the teachers, makes teachers transform from the traditional role to the new role in this information age.

Teachers in the information age need to have certain theoretical literacy. First of all, it is necessary to have a solid sense of lifelong learning, and to realize that the knowledge system is constantly updated and developed. There is a transformation not only between tacit knowledge and explicit knowledge, but also between the teacher-oriented principal and the student-oriented principal. In the information age, the high-speed flow of information will lead to more frequent conversion. Secondly, we should continue to accept all the new things that are conducive to teaching activities, such as all kinds of information teaching methods and teaching models. Thirdly, more attention should be paid to the studentcentered educational values, which should not only attach importance to the all-round development of students, but also respect the differentiated development of students. Finally, we should pay attention to the absorption of diversified educational quality evaluation view, in order to realize the combination of self-evaluation and a variety of other evaluation means, to improve a more scientific and standardized education quality evaluation system. In addition, the big data processing promoted by information technology provides a more scientific and effective means for teaching activities evaluation. Learning data analysis is a very important part of teaching, which is to realize the evolution from data to information, to knowledge and to wisdom, and it is helpful for teachers to find teaching laws and predict educational development trends. Teachers should store, mine and analyze the data of teaching activities scientifically and reasonably in order to provide scientific data support for teaching activities. [16]

\section{Concluding Remarks}

(1) MOOC is an innovation of teaching mode and teaching concept. Teachers should make use of information technology to improve teaching quality

MOOC is not only an innovation of teaching mode, but also a revolution of teaching concept and talent cultivation. It is a revolution that will influence almost all fields of the world. Undoubtedly, education is the first and the the most affected area. In the Internet era, the education industry is also undergoing a profound change led by the Internet, and the traditional "infusion" education model, in which teachers are responsible for speaking and students are responsible for listening, is gradually being changed. China's education has also entered the "Internet + " era. The introduction of online education is both an opportunity and a challenge for the reform of education in China. We must see clearly its advantages and disadvantages, find the right direction of China's education development. In short, the use of multimedia is the necessary phase of the current development of science and technology, the universities also need to use new education technology, teachers should actively change ideas, improve the traditional teaching mode through online teaching mode in order to improve their teaching quality, stimulate students' interest in learning, and guarantee the teaching effectiveness.

(2) The success of the transformation of teachers determines the success of the transformation of higher education

China's higher education is in a period of transition, which will be greatly influenced by MOOC revolution. To a large extent, the transformation of higher education depends on the transformation of college teachers, who still play the dominant role in education. The success or failure of the teachers' transformation will determine the success or failure of higher education's transformation.

(3) It is necessary to train multi-capable teachers to evaluate the teaching process based on Internet and big data technology

In the era of "Internet + " the pursuit of education is students' all-around development instead of their paper exam scores. We should pay attention to the whole teaching and learning process. Students' behavior assessment is conducted from various aspects including some academic performances such as classroom discipline, homework, grades and other non-academic performances such as inner feeling, thinking, creativity, and personality development. In the process of teaching, different learners' characteristics, learning environment, motivation and other factors will produce different teaching effects. With the help of big data, teaching evaluation can be more diversified and students' diversified development can be promoted. For teachers, big data is conducive to real-time tracking of students' learning and teachers' teaching, so as to promote interaction and understanding between students and teachers, and to avoid traditional "cramming teaching". At present, big data interaction technology is more widely applied in the business field, but less in the education field. Big data analysis on education needs such kinds of talents as those who have a certain understanding of the education and those who can analyze big data, and also those computer professionals, and even those inter-disciplinary talents who are familiar with all of the above aspects. Technological disadvantage will limit the development of online education. Therefore, it is necessary to further strengthen the research on the application of big data in education, and cultivate special interdisciplinary talents, so as to realize the educational ideal of "teaching students according to their aptitude" as soon as possible. [17]

(4) Many universities in China have set up teacher development centers to promote the career development of 


\section{teachers}

In order to promote the professionalization of teacher development, China had set up more than 30 national model centers for teacher development during "the 12th Five-Year Plan" period (the year of 2011-2015). In recent years, many more colleges and universities in China have established state-level teacher development centers, such as the University of Science and Technology of China, the Southeast University, Anhui University, etc. The establishment of the organizations shows the idea of transformation from "teacher training" to "teacher development".

(5) College teachers should follow the trend of big data era, strengthen lifelong learning and develop high-quality online open courses

College teachers should face up to the opportunities and challenges brought by MOOC to make full use of the rich and high-quality teaching resources, to change the teaching concept, to explore a variety of teaching modes, and to seek the best talent training plan. In the tide of MOOC teachers in colleges and universities should keep up with the trend of the big data era instead of being stuck in the past. Only by cultivating the consciousness of innovation and life-long learning, and devoting actively themselves to education and scientific research, especially improving information literacy, can the resource advantages of MOOC be converted into practicable advantages in their teaching. Only taking this as an opportunity, standing on a new height with a new perspective to create flexible open curriculum, can the modernization of education be realized then.

(6) College teachers should combine online teaching with traditional offline teaching instead of abandoning thoroughly the traditional education model

Online education does have some advantages that traditional education cannot match, but we should not blindly overthrow the tradition. Online education should never replace traditional education completely, it should be positioned as an important supplement to traditional education because face-to-face communication between people is still an important part of education, and teacher's guidance to students is still playing a key role in teaching as well. We should not blindly pursue technology, but should adhere to the essence of education. Integration of online and offline teaching will promote the development of education. The new era has come. All education participants should actively participate in this innovation, and make the best use of online education to promote the healthy and sustainable development of education successfully. [18]

\section{References}

[1] Li fei, Huang Mingdong. Opportunities and challenges brought by "MOOC" to universities [J]. China Higher Education, 2014 (7): 22-26.

[2] Wu Chao. Research on the construction and countermeasures of "MOOC" teaching platform for ideological and political theory courses in colleges and universities [J]. Education Exploration, 2015 (2): 144-148.

[3] Zhang Guangbin, Liu Jin, Zhou Jie. An analysis on the development of new teachers' teaching ability in universities under the background of "Internet +" [J]. Journal of Science and Technology, 2020 (2): 1-3.

[4] Wang Zhenhua. How new teachers in colleges can improve their self-teaching ability [J]. Education and Teaching Forum, 2019 (5): 49-50.

[5] Song Qiong, Zhu Xiaowei. Research and practice on the improvement of information-based teaching ability of college teachers in the era of "Internet $+"$ " $\mathrm{J}]$. Shandong Chemical Industry, 2018 (17): 146-147.

[6] Shang Feifei, Chen Yang. Application of network social platform in college English teaching [J]. Journal of Changchun Institute of Education, 2013 (17): 77-78.

[7] Jiang Bo, Wang Yijun. Perspective and countermeasures of "MOOC" [J]. China Higher Education, 2014 (7): 18-22.

[8] Chen Junxiang. Research on college curriculum and teaching reform under the development of online education [J]. Education and Teaching Forum, 2019 (10): 112-113.

[9] Zhang Bo, Zhang Lliyan. Research on effective countermeasures for the development of college teachers' professional ability in the new era [J]. China Off-Campus Education, 2020 (2): 23, 125.

[10] Wang Chen, Liu Nan. Internet + education: a great change in education in the era of mobile Internet [M]. Beijing: China Economic Press, 2015.

[11] Wu Dingchu, Liao Chongxu. On the quality of learning teachers and their on-job training [J]. Journal of Chinese Education, 2005 (10): 67-70.

[12] Wang Shi, Zhu Junkui. Investigation and research on the educational technology ability of college teachers in the context of MOOC [J]. Journal of Inner Mongolia Normal University (Education Science Edition), 2017 (8): 62-66

[13] Tian Xin, Liang Guichun. Discussion on the improvement of informatization teaching ability of young teachers in colleges - hybrid teaching based on MOOC and flipped classroom [J]. Theoretical Observation, 2015 (8): 156-157.

[14] $\mathrm{Li} \mathrm{Na}$. Cultivation and improvement of information-based teaching ability of college teachers in the era of educational informatization $2.0[\mathrm{~J}]$. Architectural Engineering Technology and Design, 2018 (34): 4202.

[15] Fu Yan, Zhang Jianxun. Reflections on the deep integration of information technology and higher education in the era of big data [J]. China Light Industry Education, 2014 (4): 9-11, 18.

[16] Dong Peng, Gu Yiran. Research on teacher development path under the background of educational informatization [J]. Journal of Economic Research, 2019 (19): 155-157.

[17] Lei Ping. Thoughts on the future development of online education [J]. Straits Science, 2018 (2): 89-91.

[18] Jiao Jianli, Wang Ping. MOOC: learning reform in the era of Internet + education $[\mathrm{M}]$. Beijing: Machinery Industry Press, 2019. 


\section{Biography}

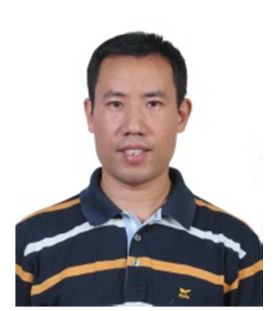

Zhou Junhua, Main research interests: Editing and publishing, education and teaching, coursebook research and development, foreign language teaching.

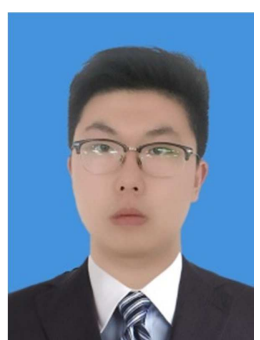

Guo Peng, Main research interests: Big data analysis and decision-making, industrial economy and statistical analysis. 